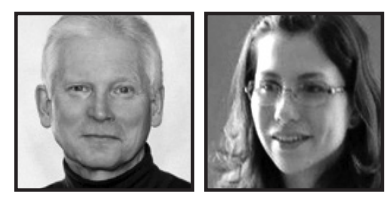

\title{
Reflecting Selves: Pre-Service Teacher Identity Development Explored Through Material Culture
}

\author{
Boyd E. White and Amélie Lemieux, McGill University
}

\section{ABSTRACT}

This article describes a research project that investigated the development of pre-service teacher identity, with an emphasis on meaning-making and articulation of personal values. The methodology is primarily arts-based. Data for the research consisted of: (1) participant-created three-dimensional constructions that symbolized their emerging values and identities; (2) accompanying written reflections that provided the context of the constructions and elaborated on the personal symbolization of the material culture involved. With this article, we hope to initiate further conversations around teacher education, professional development, and arts-based learning, with particular attention to dialogue about the teaching self.

n this article, we explore avenues to pre-service teacher (hereafter referred to as PST) self-identity, and argue that self-identity represents an essential component of teacher preparation, and eventually, in-service practice. We suggest that identity work requires attention to the development of positive selfidentity, which is tied to notions of caring - for one's self and for one's students. As Noddings (1992) has argued, it seems reasonable to suggest that students need to feel valued by their teachers in order to feel self-worth in regard to their studies. The act of valuing, on the part of teachers, requires that they know their students as individuals, beyond ranks and standardized test scores. But a first step towards knowing and valuing others is having a positive self-identity. As Parker Palmer (1998) has insisted:

When I do not know myself, I cannot know who my students are. I will see them through a glass darkly, in the shadows of my unexamined life-and when I cannot 
see them clearly I cannot teach them well. When I do not know myself, I cannot know my subject—not at the deepest levels of embodied, personal meaning. (p. 2)

To that end, we endeavour to guide our students through their personal inquiries into Parker Palmer's question: Who is the self that teaches? (p. 4). Thus, as part of a twoyear federal research grant that includes partners from two other Canadian universities, our study examines those inquiries. Our strategy is to encourage creative, material culture-based self-expression to enable student reflections upon and articulation of their evolving self-identities. In this paper we cover the results of the first phase of our ongoing research. This article thus focuses on the work of one McGill University undergraduate PST and her attempts at a creative (art-making) response to an articulation of her self-identity. We describe this in detail later in the article.

First, however, readers may find a little more context helpful. Philosophical Foundations of Education is the title of a required course in a four-year B.Ed. program within the Faculty of Education where we teach. Most students take the course in their first year of studies. One goal of the course is to introduce students to a variety of philosophical stances in regard to education. Thus students are introduced to readings by authors as varied as Plato, A. S. Neill, Martha Nussbaum, John Dewey, Nel Noddings, Neil Postman, and many others. The point of the readings is to show that there is more than one stance that one may take in regard to an educational philosophy. Students are invited to reflect on the degree to which they agree or disagree with the authors discussed, and to gradually adopt a position of their own. Most students construct a position based on the ideas of a few authors rather than on the work of any single philosopher. Their positions reflect their underlying values. But those values are not formed on the basis of readings alone. Indeed, students' daily lives, their interactions with the material world around them, are highly influential in the construction of values. The extent of those influences is not always recognized. One component of our teaching, and the specific focus of our research project, therefore, is to draw attention to the influences of material culture in the formation of teacher identities. Later in this paper we discuss our strategy in one class for highlighting that influence. In short, this paper addresses the theme of this issue-professional development in educationthrough discussion of what we hope readers will see as an innovative class assignment and its potential for expanding the boundaries of possibility. 


\section{Theoretical Framework}

The role of material culture as formative in the development of pre-service teacher identities offers a site of new epistemological understandings in teacher education. Material culture provides: (1) concrete artefacts available for empirical examination; (2) a reference point for symbolic interpretation; and (3) a lens through which to deconstruct the sometimes problematic, frequently unarticulated and even inchoate nature of student-teacher perceptions in ways that define the conditions, practices, and products of what constitutes becoming a teacher in the 21st century.

Material culture is pervasive, an omnipresent feature of our daily lives. We build on Freedman's (2003) emphasis on visual culture as a cornerstone of teacher identity:

[T] he expanding realm of visual culture is not just worthy of study because it's out there; it is worthy of study because it's in here; through art making and viewing, we shape our thinking about the world and about ourselves. (p. 91, author's emphasis)

Freedman's (2003) extensive work on visual culture provides support for our focus on concrete representations of identity: "A good illustration of the complex connection between image and meaning can be seen in the visual choices people make to reveal cultural identities" (p. 97). Interesting in Freedman's (2003) statement is the focus on decision-making (i.e., the act of choosing a material, a theme, even one colour over another, indicates preferences). These inclinations derive from our lived experiences and individual backgrounds. Thus, one's values may find expression through creative work. We endorse Madhubiti's (2014) declaration that art "is not an afterthought but a destination of the mind" (p. x). As such, Weber and Mitchell (1995) echo Madhubiti's thought:

By using popular culture itself as a conduit for self-study, it is possible to stir up the sediment of subconscious images that colours intellectual and affective life, bringing to light previously hidden aspects of popular imagery that silently shaped personal and collective conceptions of teacher. (p. 131)

While we agree with the notion of art as a mindful destination and popular culture's possible contributions to that destination, we focus on conscious awareness, however sedimented that consciousness may be. That is, our analysis of the data takes a phenomenological turn to uncover layers of "the self that teaches" (Palmer, 1998, p. 4): religious and political beliefs, community affiliations, personal tastes, 
memories, reflections, and so forth. Personal identity lies at the intersections of these phenomena. Examples of such intersections are reflected in our practice as educators when we use artefacts that have triggered our own values awareness and provided instructional insights (e.g., an excerpt from a thought-provoking movie to introduce ethical choices, a sculpture crafted by a member of an Inuit community to talk about cultural representations). When we adopt such practices, we aim to teach through our experiences, through who we are, through our values. This premise serves as a starting point for our inquiry into how the participants reflect on their identity through material constructions crafted with objects they value. That is, the PSTs see their values and beliefs embodied in the objects that mirror aspects of their teacher identities.

In making use of arts-based strategies to initiate creation of the data, our study complements others. For example, in a recent LEARNing Landscapes article, Gulla (2014) examines the processes inherent in poetic writing, with the objective of raising awareness as to how it might shape reflections on personal values and teacher identity. Other relevant studies (Ayers, 2010; Bukor, 2011, 2013; Conle, 2006; Ferrero, 2005; Knowles, Cole, \& Presswood, 1994; Palmer, 1998) focus more generally on the need to enhance educators' reflectiveness on their practice as teachers.

We not only examine how arts practices and products contribute to emerging understandings of self as a PST, but also: (1) how creativity informs pedagogical practices (Crowell \& Reid-Marr, 2013; Greene, 1991, 1995; Keller-Mathers, 2011; Robinson, 2006); (2) how visual art-making and creative writing provide a way to interrogate situated knowledge in relation to classroom experiences; and (3) how PST-created artefacts can be utilized to question meta-narratives that shape understandings of teacher identity development.

While some studies address the ongoing tensions between teachers' professional and personal selves (Palmer, 1998; Sameshima, 2007), there seems to be an overall agreement that identity work offers the possibility to bolter professional development and the intertwining of lived experiences and personal-professional relations (Cole \& Knowles, 2000). As Stenberg (2010) explains: “In order to guarantee high-quality teaching, a teacher should be aware of the sources for making pedagogical decisions; the more aware teachers are, the more they can move beyond reactionary teaching behaviour towards conscious and rational decision-making processes" (p. 331). Our aim is to advance that awareness through the fostering of PST-created threedimensional works and accompanying writings. To do so, we borrow from Connelly and Clandinin's (1988) notion of "personal practical knowledge," which is "a moral, affective, and aesthetic way of knowing one's life educational situations" (p. 59). 
In their model, the authors emphasize the importance of picturing-as a reflective tool-personal writings that cater to aspects of autobiography, and journal writing, to enhance pre-service teachers' ability to make sense of their purpose as teachers. Following Connelly and Clandinin's theory of personal practical knowledge, the tools we used in our inquiry address images, personal philosophy, metaphors, practical principles, and morals (Clandinin \& Connelly, 1986). The decisions teachers make ultimately depend on their personal practical knowledge, for it "exists in the teacher's past experience, in the teacher's present mind and body, in the future plans and actions" (Clandinin \& Connelly, 1987, p. 496). Any decision is thus conditioned by the individual's background, situatedness, and place in time.

\section{Self-Identity and Values}

In his chapter The Heart of a Teacher: Identity and Integrity in Teaching, Palmer (1998) contends that teachers fail to become "good" the very moment they-consciously or unconsciously - separate their personal from their teaching selves. He explains that robotic teaching results from disregarding one's values and preferences in an effort to decrease one's vulnerability in the classroom. As a solution, Palmer suggests selfidentity development through remembrance of our values, but also of the persons that shaped (and continue to shape) us into who we are, that is, our mentors and our students. This understanding unravels the transmission of values in three stages: (1) the transfer starts in pre-service teaching, when the mentors communicate values that teacher candidates either receive or reject; (2) it continues when those teachers working in the field transform these values into knowledge to be transmitted; and (3) it flourishes through language when teachers share the necessary knowledge, actions, and values with their students. Pre-service teachers can only learn to do this when they start to familiarize themselves with who they are, what they like and dislike, and when they reflect on that practice: "As we learn more about who we are, we can learn techniques that reveal rather than conceal the personhood from which good teaching comes" (Palmer, 1998, p. 24). Similarly, Dolloff (1999) demonstrates that, when pre-service music teachers produce written narratives that accompany visual metaphors of teacher identity, these artful expressions give them an opportunity to recollect memories about their past teaching mentors who, in turn, contributed to shape parts of their identity.

Another study conducted by Blaikie (2009) concurrently shows that visual and written representations of the mind and body are negotiated expressions of a variety of values, including but not limited to: gender, culture, religion, socio-political tendencies, and sexual orientation. In the process of being aware of self, art-making 
allows for various ways of investigating layers of the self, dimensions that are worthy of attention, but often difficult to grasp. Thus, through the creation of different art forms (e.g., drawings, poems, paintings, sculptures), or what Knowles, Cole, and Presswood (1994) call "artefacts of experience" (p. 23), such self-inquiries become possible.

Self-inquiry also addresses the capacity to make decisions that are, in turn, infused with embedded values. Often, teachers make decisions within clear dichotomous educational contexts: "Teaching ... involves preference and value, obligation and choice, trust and care, commitment and justification" (Ayers, 2010, p. 32). The task remains difficult, as Ayers (2010) explains: "A generative challenge in teaching is to decide who you want to be as a teacher, what you care about and what you value" (p. 36, our emphasis). Our project is one way to address these questions.

Attention to individual and collective values is crucial, not only in this study, but to indicate more broadly how teachers make sense of moral values that ought to be present in the profession. Made daily, moral decisions determine the actions teachers undertake on behalf of their students and for themselves. Ideally, conversations and discussions about values would lead to reflections that could ultimately improve some aspects of the schooling system:

We need to talk of values - of what ought to be-if we are ever to really understand ourselves, our situations, and our options, and if we are ever to undertake meaningful action toward improvement in schools or in society. (Ayers, 2010, pp. 36-37)

\section{Modus Operandi}

To assist our students in addressing the values embedded in their self-identities, we employed two strategies: 1) participant-made constructions of what we have called "identity boxes," which are three-dimensional constructions made from found materials, and 2) accompanying commentary that detailed the thoughts and feelings behind their work. Participants, few of whom have any art background, assembled their constructions, including various compartments into which they placed items that symbolize facets of their evolving identities. The boxes provide a concrete object for personal and shared reflections. To address our second strategy, most students employed standard essay writing. Others attempted more poetic interpretations such as ekphrasis (i.e., "an elaboration upon the viewer's experience and a creative endeavour in its own right" [White, 2013, p. 110]). The latter tends to emphasize the affective nature of the encounter (Moorman, 2006; Mansoor, 2014). 
Specifically, in the fall term of 2014, as part of the course described earlier, we offered as an option for a final assignment the creation of individual three-dimensional objects that participants felt symbolized their teacher identity. Below is a description of the option:

Option D. In our first class I introduced the idea of constructing "identity boxes." As you saw, these can take an infinite variety of 3-D forms, so I invite you to use your creativity; there is no formula. However, your identity box should provide as clear a portrait of you as possible. By portrait, I don't mean photograph. I mean what symbols (religious, ethnic, pop culture, job logo, etc.) can you use to describe various aspects of yourself? Your box can also contain papers you have written for this course or others, or just snippets of those papers. Find a little compartment to slide those into. Do you do any creative writing, not course related? If so, that's an important part of your identity. Are there elements of your identity that you want to express but are not yet ready to share? If so, put a little lock on that part. Provide a one-page (at least) accompanying written document to assist in the interpretation of your 3D work. There are no size limitations to your construction; you (and I) just have to be able to lift it. I will photograph your work and return it to you.

As the above option description indicates, we told the students during their first class their options for the final assignment. We showed numerous examples of threedimensional works, from art students, professional sculptors, to architects (e.g., Habitat 67), and notably, creations by non-artist gay seniors who were exploring their memories of self-identity. These last were, in fact, the inspiration for the course option, and memories certainly played a role in our students' works too. Students had the whole term to work on their constructions. Less adventurous students interpreted the word "box" very literally, thus limiting their explorations of possible forms. Others, however, interpreted the instructions widely, which is what we had hoped to see. Indeed, one student said that she deliberately tried to operate "outside the box." The varied responses to the option created an assessment challenge. On what bases were we going to assign a grade? How indicative of the PSTs' self-identities were the constructions? To address such questions, we used a mixture of "portraiture" (LawrenceLightfoot \& Hoffmann Davis, 1997), ethnography (Anderson, 1989; LeCompte, Preissle, \& Tesch, 1993; Pink, 2002), arts-based and arts-informed methodology (Butler-Kisber, 2010). Through these perspectives we studied "how material forms and visual images are central to the socialization of human beings into [education] culture" (University College London, segment on material culture, p. 1). That is, we investigated the belief systems, behaviours, and perceptions of our student participants through their created artefacts (Purcell, 1983; Schlereth, 1982). 
To build their boxes, some students chose shoeboxes and the like, popular and convenient materials. Others used alternative pre-made forms (e.g., wood or plastic frames, luggage pieces, small bookshelves, even stools) as containers for their statements. Still others made their works from raw materials such as clay. In some cases the choice of materials and specific content was obvious. In other cases we needed the PST's input on the context and content-the commentary part of the exercise-to understand the work. We were flexible about the format of these written reflections. Consequently, the results point to a range of genres. Some used standard expository statements. Others explored poetic responses.

Each participant scheduled a 20-minute individual meeting with us in our Faculty of Education library, where we had designed and set up a photography booth. The objective of this session was primarily to give all PSTs the opportunity to showcase their piece and have pictures taken of the created work. We took several photographs of each artefact, from different angles and varied emphases. The photographs, written commentary, and in-person discussions formed the data for our inquiry. Approximately half the class of 120 students chose Option D. Due to word limits we cannot address all of those efforts here.

Below, we present the work of one PST, a typical example of a participant-generated identity box.

\section{Exemplifications}

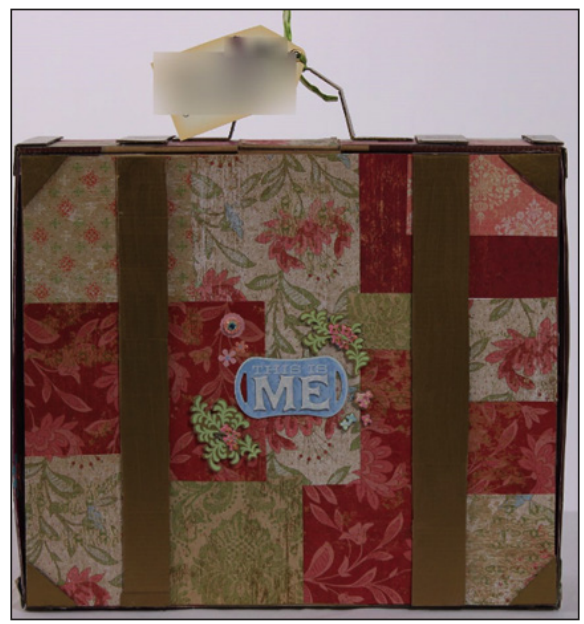

Fig. 1: Outside the box-Megan's artefact 
We will call our participant Megan. Her identity box took the form of a beige and burgundy suitcase (Figure 1), made from cardboard and scrapbook sheets. Three visual conventions or signs allow us, from a denotation perspective (Barthes, 1967, 1977) to interpret her box as a piece of luggage: 1) the handle implies that the box can be carried; 2 ) the tag (blurred for anonymity reasons) shows the participant's name and her return address; and 3 ) the maroon corners and vertical straps remind us of the suitcases of the mid-20th century. Megan describes her box as such:

I wanted to see how creative I could get with using a large shoebox as my base... I create[d] a vintage suitcase because I'd like to think my life is an adventure and the elements in this suitcase are what I have kept closest to me during this journey thus far.

The meaning of the image is literal in this case (i.e., Megan chose to build a suitcase). Her accompanying commentary confirms that she chose what she felt to be relevant elements to convey her message- "life as an adventure"-and aid in her reflections. Her message is both explicit and implied (Barthes, 1967, 1977). Her thoughts on identity guide her choices of material and form.

Inside her identity box, Megan chose explicit, denotative terms to express parts of her desires towards identity as teacher: "Around the top of my box I incorporated the three words: live, laugh, and love. These three words summarize what I would like my life to consist of" (Figure 2). Another explicit word, central in her construction, is travel: "I love being in a new place and soaking up as much culture and knowledge I can while visiting."

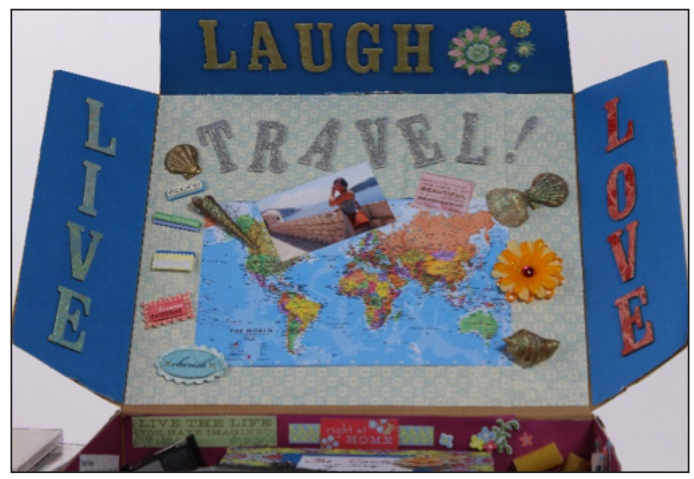

Fig. 2: Inside the box-Top cover of Megan's artefact 
Using bold, capitalized, and colourful letters, Megan intertwines these four termslive, love, laugh, travel-as central in this top cover. We note that the use of images in this frame is scarce. Instead, Megan used words that might be considered as directives, or a mandate, and a central map that suggests an emphasis, when placed below "TRAVEL!" The term "travel" might refer here to the destination rather than the action of travelling exemplified by the map. In other words, the visual supports countries and cities, rather than the means of travel (i.e., a destination, and the experiences that these trips bring).

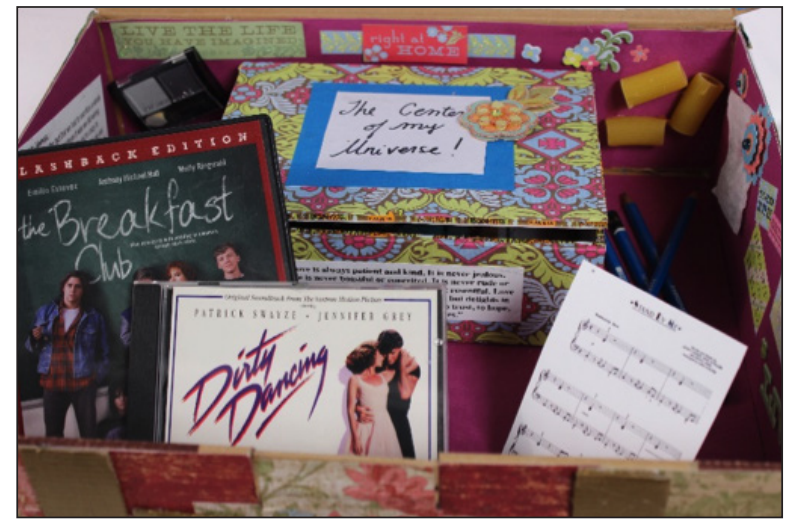

Fig. 3: Multilayered aspects: A box within a box

In her reflections, Megan speaks to the various elements she incorporated in her frame. Visible in Figure 3 is an apple green, magenta, and sky blue box. Megan called this "The Center of my Universe," in which she incorporated the pictures of influential mentors and persons. Within the box, she wrote adjectives that "best describe [her] character: relaxed, creative, warm, optimistic, passionate, loyal, dreamer, elegant, and caring."

We see, in Megan's identity construction, that she relies on words, but also visual images, and objects that signify her being as a PST. Megan also explains that the film The Breakfast Club sparked her interest in writing poetry for this project. In this case, Megan writes that a scene in the movie (as shown in a letter to the teacher, Figure 4) prompted her to give poetry a try. 


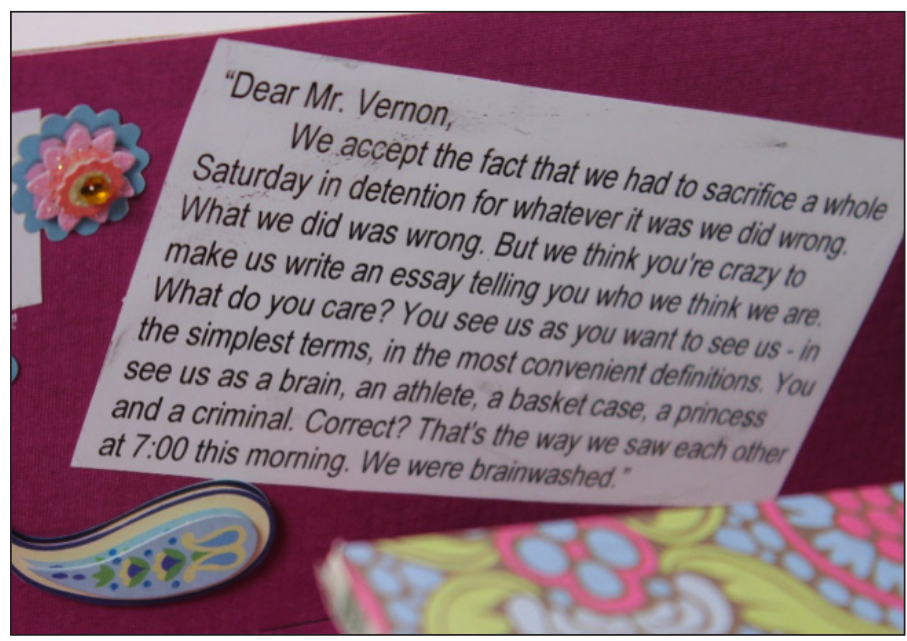

Fig. 4: Letter to the teacher from the film The Breakfast Club (Tanen, Hughes, \& Hughes, 1985)

This quote is what inspired me to write my poem for this identity box. The reason ... I love it so much is that, as a teacher, I want to make sure to never judge my students according to what I think they are. I want my students to be able to define themselves. I want them to feel safe enough to show me who they truly are.

\section{Megan's Accompanying Poetry}

I can spend my life trying to figure out who I am,

I am fixated on the idea

Shouldn't I already be someone?

This box is not me

It is merely a box filled with objects

Things that I keep closest to heart

They do not define me

They contribute to ' $\mathrm{l}$ '

The 'I' that I am creating

The 'l' of today

Is not the 'I' of yesterday,

Nor will it be the 'I' of tomorrow 


\section{A Brief Commentary on Megan's Poetry}

Megan's poem suggests that she is aware of her current self-_"shouldn't I already be someone?" At the same time, she acknowledges in her first line that her "self" is an ongoing project. Her question, however, hints at a certain resistance to the idea that her current identity may not be enough, although the final lines acknowledge the inevitable changes. Megan is also well aware that the suitcase is not "her." It is "merely a box." But she is also aware that symbols have the power to represent her. They contribute to "I."

An initial examination of Megan's self-identity, as portrayed in her "suitcase" and her accompanying commentary, shows certain affinities and values that we portrayed diagrammatically:

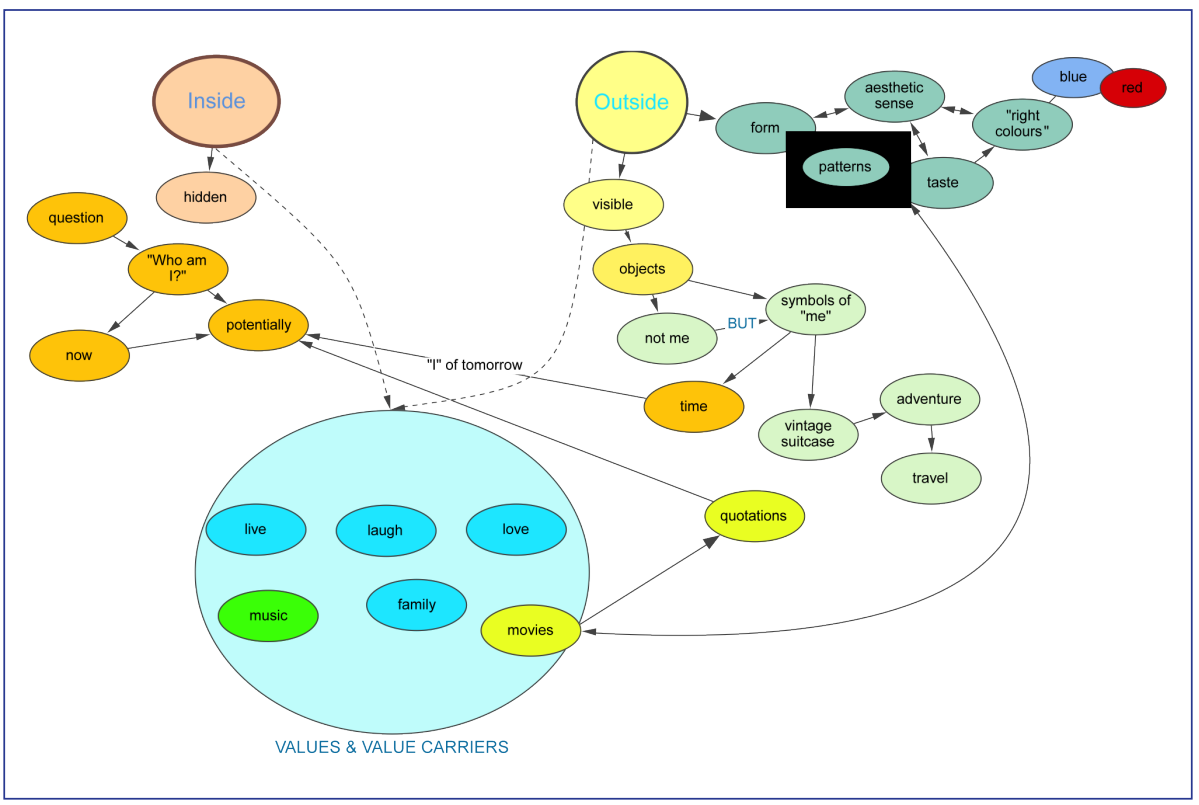

Fig. 5: A diagram situating Megan's values and identity work

The diagram is a complement to what we provided above on Megan's poetic selfexplorations and examines further Megan's own written commentary on her suitcase. What we hope the diagram makes clear are the contributions to a few of her values, both "inside" and "outside" manifestations. No doubt Megan has many other values that are not represented here. For example, we do not know whether she has the patience that a teacher should have. Megan did not address that quality. However, what she did mention explicitly shows up as core values. The diagram refers to qualitative responses 
to features of Megan's life. That is, movies, family, or music, are not the values, but her responses to them are. Those three items are the carriers of values. We can see or hear those phenomena. Similarly, laughter is a phenomenon that we can hear, but the directive to laugh is a qualitative stance, a way of greeting the world. Even the word "live" has an implied directive, rather than being a specific concrete object. Whereas, we cannot "see" love, love is embedded in certain actions that we interpret as that quality.

\section{Educational Significance}

In this paper we have tried to demonstrate one pathway, through attention to arts-based participant-created artefacts, to PST self-identities. Our study, we hope, has the potential to demonstrate the viability and practicality of incorporating the arts more centrally in teacher education programs. That is, arts-based assignments can be used as teaching tools within the teaching profession, and integrated into teacher education research. Increased understanding of connections between arts-informed self-definition and successful, satisfying teaching practice may enable pre-service education programs, education ministries, curriculum designers, and school boards to adopt strategies to address current rates of new-teacher attrition. Benefits to nonresearchers, such as classroom teachers and educational policy makers, rest in the model we provide for a focus on the arts across the curriculum as a way to engage students in embodied, holistic learning.

\section{Concluding Remarks}

An objective of this paper has been to contribute to the ongoing dialogue in teacher education regarding ways to deepen teacher candidates' understanding of their values and self-identities. In so doing, we acknowledge the limitations of our study. As Palmer (1998) notes: "identity... can never be fully named or known by anyone, including the person who bears [it]" (pp. 13-14). Nonetheless, we hope that we have demonstrated that creative and artful constructions of identity open certain windows into pre-service teachers' selves, albeit with an example from only one student.

We have defended the need for an arts-based contribution to professional development as it acknowledges PSTs' actual material culture and world they live in. We started by reviewing and acknowledging the ongoing contributions of visual representations of teacher identity. In a section on self-identity and values, we noted that decision-making is part of identity construction, and that through material choices in constructing identity boxes, PSTs can further reflect on who is the "self that teaches" (Palmer, 1998). With Megan's example, we showed that one can discern moments that 
influenced her as a PST, and terms that capture her evolving sense of self. Her popular culture references to movies such as The Breakfast Club were helpful in that discovery. The quotation she chose from that movie speaks to a representation of the pedagogical dynamics that were influential to her teacher identity. This discovery echoes Weber and Mitchell's (1995) statement on the role of popular culture in that endeavour: "How people think about teaching may be shaped in many ways by the images of teacher in popular culture that they encounter in their daily lives" (p. 20). Our task in this paper has been to draw attention to the various ways pre-service teachers make sense of that role through visual representations of themselves and the material representations they value.

Most teachers today use popular culture in their classrooms. In a popular cultureinfused world, attention is drawn to what meets the eye and shapes the lenses through which we see ourselves, others, and the world we live in. Our hope is that this lens can be adjusted through reflections on the self, not only in written form, but also supported with visual and kinesthetic constructions designed to capture the multiple layers of individual identities. The implications of our study are that attention to material and popular culture can be a beneficial and freeing means to learning. We have argued that teachers need to be aware of their teaching selves, their choices, and preferences that inform their pedagogical practice (Ayers \& Ayers, 2014), and that professional development can benefit from such artful inquiries into the self. For, identity work lies at the crossroads of experiences, choices, and events. With a deeper look into "artifacts of experience" (Cole, Knowles, \& Presswood, 1994, p. 23), we suggest in this study that, when PSTs are given the directive and opportunity to explore and symbolize their self-identities, creative artful inquiry can provide one avenue towards that articulation. What we have described here is based on an initial experiment in one class. In future we might want to augment the exercise with initial small-group conversations about the underlying tensions and positive messages of identity work as a base for professional development. Students could also hold critiques of peers' works in progress, encouraging increased attention to the relation between form and content as they grapple with the intricacies of meaning-making in regard to the "self that teaches."

\section{Acknowledgments}

This research is funded by the Social Sciences and Humanities Research Council of Canada. 


\section{References}

Anderson, G. (1989). Critical ethnography in education: Origins, current status, and new directions. Review of Educational Research, 59(3), 249-270.

Ayers, R., \& Ayers, W. (2014). Teaching the taboo: Courage and imagination in the classroom. New York: Teachers College Press.

Ayers, W. (2010). To teach: The journey of a teacher (third edition). New York: Teachers College Press.

Barthes, R. (1967). Elements of Semiology (trans. A. Lavers \& C. Smith). London: Jonathan Cape.

Barthes, R. (1977). Image-music-text. London: Fontana.

Blaikie, F. (2009). Knowing bodies: A visual and poetic inquiry into the professoriate. International Journal of Education \& the Arts, 10(8), 1-33. Retrieved from http://files.eric. ed.gov/fulltext/EJ859039.pdf

Bukor, E. (2011). Exploring teacher identity: Teachers' transformative experiences of re-constructing and re-connecting personal and professional selves. Unpublished doctoral thesis, Ontario Institute for Studies in Education at the University of Toronto, 397 pages. Retrieved from https://tspace. library.utoronto.ca/bitstream/1807/31700/6/ Bukor_Emese_201111_PhD_thesis.pdf

Bukor, E. (2013). The impact of personal and professional experiences: Holistic exploration of teacher identity. Working Papers in Language Pedagogy (WoPaLP), 7, 48-73.

Butler-Kisber, L. (2010). Qualitative inquiry: Thematic, narrative and arts-informed perspectives. Thousand Oaks, CA: Sage Publications.

Clandinin, J., \& Connelly, M. (1986). Rhythms in teaching: The narrative of teachers' personal practical knowledge of classrooms. Teaching and Teacher Education, 2(4), 377-387.

Clandinin, J., \& Connelly, M. (1987). Teacher's personal knowledge: What counts as personal in studies of the personal? Journal of Curriculum Studies, 19(6), 487-500.
Cole, A. L., \& Knowles, J. G. (2000). Researching teaching: Exploring teacher development through reflexive inquiry. New York: Alynn \& Bacon.

Conle, C. (2006). Teachers' stories, teachers' lives. New York: Nova.

Connelly, M., \& Clandinin, J. (1988). Teachers as curriculum planners: Narratives of experience. Toronto, ON: OISE Press.

Crowell, S., \& Reid-Marr, D. (2013). Emergent teaching: A path of creativity, significance, and transformation. Plymouth, UK: Rowman and Littlefield.

Dolloff, L. A. (1999). Imagining ourselves as teachers: The development of teacher identity in music teacher education. Music Education Research, 1(2), 191-207. Retrieved from http://www.auburn.edu/academic/clas ses/ctmu/7910-7916/philosophyreadings/ Dolloff.pdf

Ferrero, D. J. (2005). Pathways to reform: Start with values. Educational Leadership, 62 (February), 8-14.

Freedman, K. (2003). Teaching visual culture: Curriculum, aesthetics, and the social life of art. New York: Teachers College Press.

Greene, M. (1991). Aesthetic literacy. In R. A. Smith \& A. Simpson (Eds.), Aesthetics and arts education (pp. 149-161). Urbana and Chicago: University of Illinois Press.

Greene, M. (1995). Releasing the imagination: Essays on education, the arts, and social change. San Francisco: Jossey-Bass.

Gulla, A. N. (2014). Myth, metaphor, and metacognition: Shaping voice and identity through poetry in teacher education. LEARNing Landscapes, 8(1), 139-152.

Keller-Mathers, S. (2011). Building passion and potential for creative learning in higher education. Collected Essays on Teaching and Learning (Vol. IV), 1-8.

Knowles, J. G., Cole, A. L., \& Presswood, C. S. (1994). Through preservice teachers' eyes: Exploring field experiences through narrative and inquiry. New York: Macmillan. 
Lawrence-Lightfoot, S., \& Hoffmann Davis, J. (1997). The art and science of portraiture. San Francisco: Jossey-Bass.

LeCompte, M. D., Preissle, J., \& Tesch, R. (1993). Ethnography and qualitative design in educational research. San Diego, CA: Academic Press.

Madhubuti, H. R. (2014). Knowledge, kindness, skills, and, need I say, love. In R. Ayers \& W. Ayers, Teaching the taboo: Courage and imagination in the classroom (pp. vii-x). New York: Teachers College Press.

Mansoor, A. (2014). Ekphrastic practices in catalysing creative writing in undergraduate ESL classrooms. International Journal for the Practice and Theory of Creative Writing, 11(2), 208-227.

Moorman, H. (2006). Backing into ekphrasis: Reading and writing poetry about visual art. English Journal, 96(1), 46-53.

Noddings, N. (1992). Caring. In N. Noddings, The challenge to care in schools: An alternative approach to education (pp. 15-27). New York: Teachers College Press.

Palmer, P. (1998). The heart of a teacher: Identity and integrity in teaching. In P. Palmer, The courage to teach (pp. 8-33). San Francisco: Harper and Row.

Pink, S. (2002). Doing ethnography: Images, media and representation in research. London: Sage.

Purcell, C. W. Jr. (1983). The history of technology and the study of material culture. American Quarterly, 35(3), 304-315.
Robinson, K. (2006). How school kills creativity [Video file]. Retrieved from http://www.ted. com/talks/ken_robinson_says_schools_ kill_creativity.html

Sameshima, P. (2007). Seeing Red-a pedagogy of parallax: An epistolary bildungsroman on artful scholarly inquiry. Amherst, NY: Cambria Press.

Schlereth, T. J. (Ed.). (1982). Material culture studies in America. Nashville, TN: American Association of State and Local History, 3.

Stenberg, K. (2010). Identity work as a tool for promoting the professional development of student teachers. Reflective Practice: International and Multidisciplinary Perspectives, 11(3), 331-346. Retrieved from http://dx.doi.org/10.1080/14623943.2010.49 0698

Tanen, N. (Producer), Hughes, J. (Producer), \& Hughes, J. (Director). (1985). The Breakfast Club [Motion picture]. United States: Universal Pictures.

University College London, Material Culture. (2013). Segment on Anthropology and Material Culture. Retrieved from http://www. ucl.ac.uk/anthropology/material-culture

Weber, S., \& Mitchell, C. (1995). 'That's funny, you don't look like a teacher'. Interrogating images and identity in popular culture. London: The Falmer Press.

White, B. (2013). Pay attention, pay attention, pay attention. In B. White \& T. Costantino (Eds.), Aesthetics, empathy and education (pp. 99-116). New York: Peter Lang. 


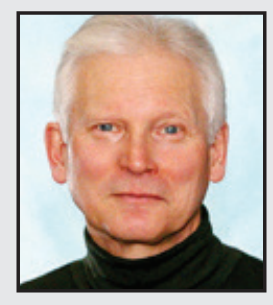

Boyd E. White is an Associate Professor and long-time member of McGill University's Faculty of Education. His research and teaching interests include philosophy of education, ethics, art education, aesthetics, and art criticism. Dr. White has written numerous journal articles. Text chapters include: ReVisions: Readings in Canadian Art Teacher Education (3rd ed.), Starting with... (3rd ed.) and What works: Innovative strategies for teaching art. Recently, he has published two texts: Aesthetics Primer (2009), Peter Lang Publishing, and Aesthetics Education for the 21st Century, co-edited with Tracie Costantino, (2010), Sense Publishers. From 2001 to 2007 he served as editor of the Canadian Review of Art Education: Research and Issues.

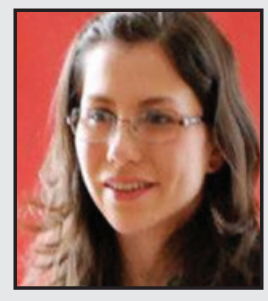

Amélie Lemieux is an educator and researcher whose research interests revolve around artful inquiry, visual and written arts, aesthetics in art education, and literacy practices in the 21st century. Her original contributions to literacy and aesthetic reception were recognized by the Social Sciences and Humanities Research Council of Canada (SSHRC), especially with Joseph-Armand Bombardier Scholarships both at the Master's and PhD levels. Now a doctoral candidate at McGill University, her research investigates youth's engagement in reading and suggests strategies for developing critical perspectives in the literature classroom. 